\title{
Comparing permeability of matrix cover types for the marsh rice rat (Oryzomys palustris)
}

\author{
Scott A. Cooney $\cdot$ Eric M. Schauber • \\ Eric C. Hellgren
}

Received: 18 August 2014 / Accepted: 7 March 2015/Published online: 18 March 2015

(C) The Author(s) 2015. This article is published with open access at Springerlink.com

\begin{abstract}
Context Matrix land cover types differ in permeability to animals moving between habitat patches, and animals may actually move faster across lesssuitable areas. Marsh rice rats are wetland specialists whose dispersal crosses upland matrix.

Objectives Our objectives were to (1) compare matrix permeability for the marsh rice rat among upland cover types, (2) compare permeability within versus outside perceptual range of the wetland, and (3) explore intrinsic and extrinsic features influencing matrix use and permeability.

Methods We quantified permeability of grassland, crop field, and forest to the marsh rice rat during

Electronic supplementary material The online version of this article (doi:10.1007/s10980-015-0185-5) contains supplementary material, which is available to authorized users.
\end{abstract}

\section{S. A. Cooney}

Department of Zoology, Cooperative Wildlife Research Laboratory, Southern Illinois University, Carbondale, IL, USA

E. M. Schauber $(\varangle) \cdot$ E. C. Hellgren

Department of Zoology, Cooperative Wildlife Research

Laboratory and Center for Ecology, Southern Illinois

University, Carbondale, IL, USA

e-mail: schauber@siu.edu

Present Address:

E. C. Hellgren

Department of Wildlife Ecology and Conservation,

University of Florida, Gainesville, FL, USA
2011-2012, by marking rats in wetlands and estimating the slope of capture rate versus distance $(0-95 \mathrm{~m})$ into the matrix. We also compared permeability within $(0-15 \mathrm{~m})$ and beyond the perceptual range of rice rats, and tested whether age, sex, time, water depth, rice rat abundance, and vegetation density influenced matrix use and permeability.

Results Permeability was greater for soybean fields than grassland or forest but did not appear to differ within versus beyond rice rats' perceptual range. Matrix capture rates were higher early in the study and in times and locations with thick ground vegetation and high rice rat abundance in the wetlands. Rice rats captured in the matrix were younger than those in wetland patches.

Conclusions Our findings expand known matrix use by marsh rice rats, and support permeability being high in matrix types dissimilar to suitable habitat. Studying individual movements will help identify mechanisms underlying enhanced permeability in crop fields.

Keywords Agriculture - Connectivity - Edge .

Movement $\cdot$ Perceptual range $\cdot$ Wetland

\section{Introduction}

The distribution of resources across landscapes is of great interest to ecologists, specifically when suitable habitat is clumped and highly fragmented (Wiens et al. 1985; Lidicker 1999). Though separated by stretches of 
unsuitable landcover (known as the matrix), populations occupying suitable habitat can remain functionally connected through occasional inter-patch movement (Hanski 1994). Landscape connectivity refers to the ease and frequency of animal movement between habitat patches and is often viewed as a structural feature of the landscape (Taylor et al. 1993; Zollner and Lima 1999). Connectivity contributes to metapopulation persistence by increasing the likelihood of recolonizing empty patches and allowing individuals to expand into new territory (Tefler et al. 2001; Moilanen and Nieminen 2002; Bode et al. 2008). Measuring connectivity can determine whether animal populations persist in a fragmented landscape and how they can be conserved (Schooley and Branch 2005).

Traditional metapopulation models quantify habitat connectivity by the size, shape, and isolation of patches within the matrix, often viewing the landscape as a dichotomy of suitable and unsuitable landcover (Hanski 1994; Zollner and Lima 1999; Moilanen and Nieminen 2002). Recently, ecologists have given more attention to the idea that the matrix comprises a spectrum of landcover types, each with a different level of resistance to animal movement (Ricketts 2001). Resistance can be measured as an individual's reluctance to cross a boundary, the physical cost of the movement, or increased mortality risk (Zeller et al. 2012). Resistance can result from the perceived level of risk to entering the matrix (Fahrig 2007), the quality of the habitat being dispersed from (Roe et al. 2009), or the social pressures pushing individuals to disperse (Remy et al. 2011). By quantifying the resistance of landcover types in the matrix, researchers can predict the direction of dispersal in the landscape and estimate overall habitat connectivity (Ricketts 2001).

Matrix permeability, which is the converse of resistance, is the extent to which elements of the landscape either allow or encourage animal movement (Kuefler et al. 2010). Often, research on matrix permeability confounds the willingness of an animal to leave suitable habitat with the ability of that animal to disperse across the matrix (Schooley and Wiens 2004). Kuefler et al. (2010) found landcover types that Appalachian brown butterflies (Satyrodes ppalachia) readily entered were used for short-term forays rather than the long-distance, straight-line movements that characterize dispersal. Haynes and Cronin (2006) also found that plant hoppers (Prokelisia crocea) took longer straight-line steps in mud-flat cover than they did in highly preferred brome (Bromus ssp.) and cordgrass (Spartina ssp.) cover types. When dispersal corridors are absent, less preferred matrix cover can be very permeable as dispersers make faster, straighter movements in such areas (Bowne et al. 1999).

As Fahrig (2007) suggests, "Animals that evolved in landscapes with patchy habitat and risky matrix should also evolve the ability to detect suitable habitat from a distance." For species that react differently to the edge of the habitat than the interior of the matrix, the extent of edge responses would be dictated by the distance into the matrix at which habitat could still be perceived (Lidicker 1999). When suitable habitat is beyond the perceptual range of the individual, animal movements may only be impacted by the composition of the unsuitable matrix (Schooley and Branch 2005, Prevedello et al. 2010). By quantifying matrix permeability at different distance scales (the habitat edge and the interior matrix), researchers can identify and compare landcover types that animals readily enter (Stamps et al. 1987), and those that are highly permeable to long-distance dispersal (Rehmeier et al. 2004).

The marsh rice rat is a semi-aquatic rodent that occupies salt and freshwater marshes throughout the southern and eastern United States (Harlan 1837; Negus et al. 1961; Wolfe 1982; Hofmann et al. 1990). Suitable habitat for the marsh rice rat consists of herbaceous vegetation within permanent or ephemeral water sources (Negus et al. 1961; Wolfe 1982; Hofmann et al. 1990). In southern Illinois, Eubanks et al. (2011) found that marsh rice rat presence in and near wetlands was positively correlated with dense stands of emergent vegetation, and negatively associated with bare or rocky ground. Although previous studies have reported marsh rice rats in grassy upland habitats (Wolfe 1982; Kruchek 2004), Wolfe (1982) described these individuals as "transients" whereas Kruchek (2004) believed the upland was being used as a refuge during flooding events. Based upon unsuccessful trapping attempts by Wolfe (1985) and Franz et al. (1998), upland forests have been considered unsuitable for rice rats (Schooley and Branch 2005). No rice rat captures in dry crop fields in any portion of their range have yet been reported (Goertz and Long 1973; Wolfe 1982; Hofmann et al. 1990).

Over the last two centuries, Illinois wetlands have undergone significant reduction and isolation due to 
human development (Suloway and Hubbell 1994). Marsh rice rats in Illinois are believed to persist in a regional metapopulation within the southern portion of the state (Eubanks et al. 2011). With $>65 \%$ of southern Illinois in agriculture production (Qin and Flint 2000), corn and soybean fields may act as barriers to rice rat dispersal, thus further isolating fragmented wetlands (Eubanks 2009). Although Hofmann et al. (1990) believed that rice rats disperse via roadside ditches and railroad rights-of-way, no research has tested the frequency and extent of rice rat dispersal through dry upland cover types. Our objectives were to (1) compare matrix permeability for the marsh rice rat in 3 upland cover types, (2) compare permeability within perceptual range of the wetland edge with permeability farther into the matrix, and (3) test whether intrinsic (sex and age) and extrinsic (local vegetation density, rice rat abundance, wetland inundation, and date) features influence matrix use and permeability.

\section{Methods}

Researchers have often translocated animals to quantify matrix permeability, examining metrics such as the tortuosity of movement pathways (Haynes and Cronin 2006), net displacement distances (Schooley and Wiens 2004), and rates of return to home territories from novel patches (Gobeil and Villard 2002). However, permeability measures that allow individuals to willingly enter and move through unsuitable landcover will permit researchers to make stronger inferences regarding landscape connectivity. Our approach was to collectively mark rice rats within habitat patches and measure permeability by quantifying how capture rates decline with distance into matrix.

\section{Study area}

Our study occurred from February 2011 to January 2012 within the 3400 ha Burning Star 5 Natural Wildlife Area, a reclaimed coal mine $5 \mathrm{~km}$ east of DeSoto, IL, USA $\left(37^{\circ} 50^{\prime} 21^{\prime \prime} \mathrm{N}, 89^{\circ} 10^{\prime} 56^{\prime \prime} \mathrm{W}\right.$; Fig. 1). At the time of this study, Burning Star 5 was owned by CONSOL Energy (Elkville, IL, USA) and managed by the combined efforts of the Illinois Department of Natural Resources, the National Wild Turkey
Federation, and the Cooperative Wildlife Research Laboratory at Southern Illinois University Carbondale. Located along the Little Muddy River, Burning Star 5 is composed of approximately 1600 ha of cropland, 800 ha of timber, 400 ha of grassland, and 560 ha of lakes and wetlands (Illinois Department of Natural Resources 2011). Landcover is diverse, with mature oaks (Quercus spp.) and hickories (Carya spp.) dominating bottomland forests; tall fescue (Festuca spp.), switchgrass (Panicum virgatum), and big bluestem (Andropogon gerardii) within grasslands; and corn (Zea mays), soybeans (Glycine max), sorghum (Sorghum spp.), and wheat (Triticum spp.) grown in croplands (Delahunt 2011).

Trapping procedures and site selection

We used Sherman live-traps (H. B. Sherman Traps, Tallahassee, Florida, USA) baited with mixed birdseed for all trapping performed in this study. We also placed 2-3 g of polyfiber bedding in traps on nights colder than $10^{\circ} \mathrm{C}$. As rice rats are nocturnal (Wolfe 1982), we set and baited traps in the early evening between 1400 and $1800 \mathrm{~h}$. We checked traps the following morning between 0600 and $1000 \mathrm{~h}$ to ensure animals were not left in traps for $>12 \mathrm{~h}$. For each rice rat captured, we recorded the location with a waypoint on a Garmin 60CSx handheld global positioning system (GPS; Garmin Inc., Olathe, Kansas, USA) and processed the animal prior to releasing it at the trap where it was captured. Non-target animals were identified to species, recorded, and released at the initial point of capture. All traps were closed during the day (from 1000 to $1400 \mathrm{~h}$ ) to avoid non-target captures.

Captured animals were handled in accordance with an approved protocol (IACUC protocol 10-009), which included anesthetizing rice rats by inhalation of Isoflurane (Isothesia, Fisher Scientific, Pittsburgh, Pennsylvania, USA) to reduce capture stress. We first recorded whether rice rats were novel captures and weighed them with a Pesola spring scale (Pesola, Kapuskasing, Ontario, Canada). While each rice rat was under anesthesia, we recorded body length, tail length, hind foot length, sex, and breeding condition of the animal. We assigned age classes based a modified Negus et al. (1961) method, which grouped rice rats $<30 \mathrm{~g}$ as juveniles, between 30 and $50 \mathrm{~g}$ as subadults, and $>55 \mathrm{~g}$ as adults (Wolfe 1985). Rice rats between 
Fig. 1 Burning Star 5 Natural Wildlife Area in northwest Jackson County, near DeSoto, Illinois, showing property boundary and four wetland sites

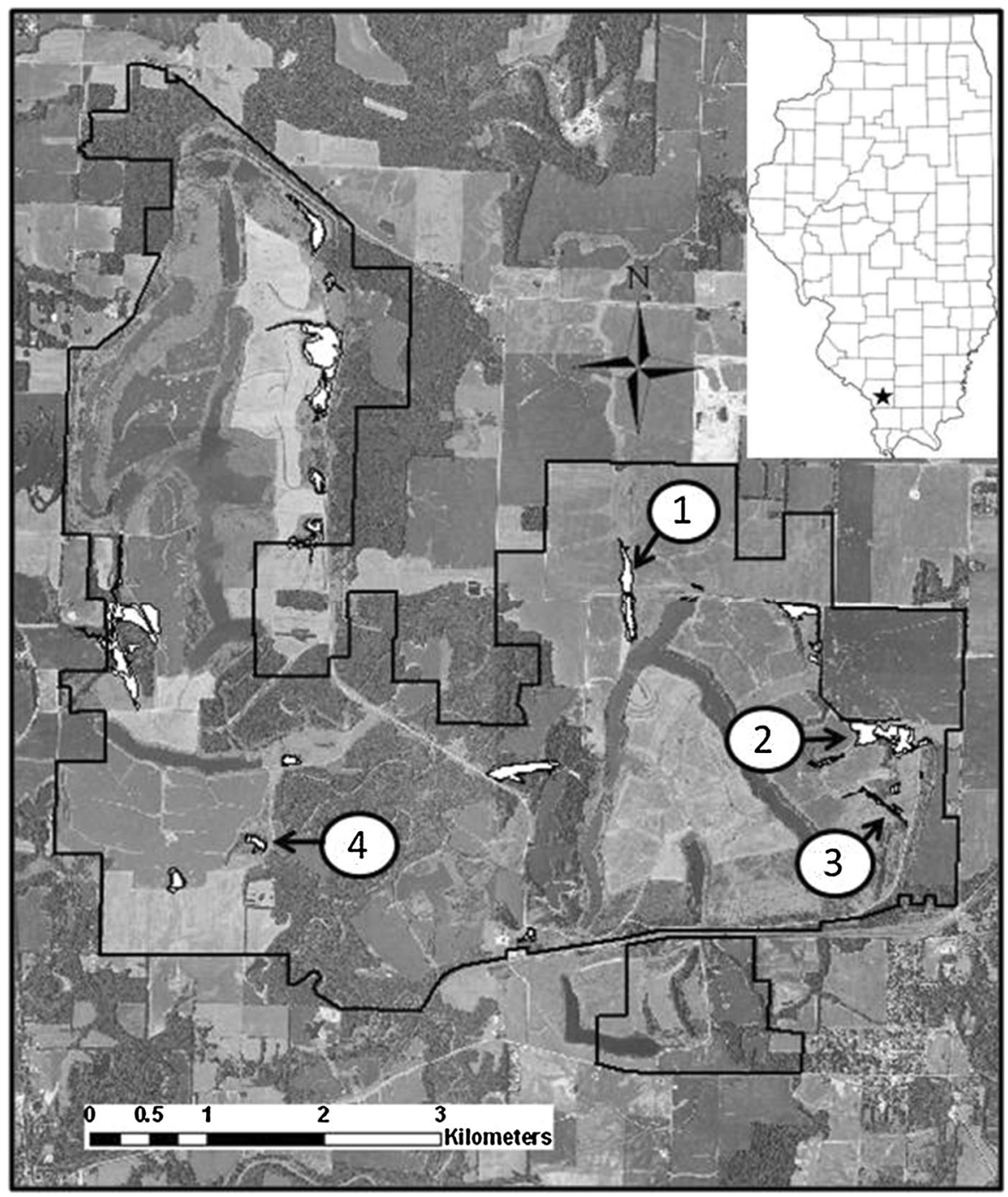

50 and $55 \mathrm{~g}$ were placed in the adult age class if they exhibited adult breeding conditions (descended testes in males and perforated vaginas in females), otherwise they were considered subadults (Wolfe 1985). Rice rats were given a passive integrated transponder (PIT tag; Biomark 9.HG, Biomark, Boise, Idaho, USA) injected into the dorsal skin between the scapulae to identify individual animals upon recapture. We removed the 5th toe of the right hind foot as a precautionary mark in case of PIT tag loss or failure. All animals were allowed to recover from the anesthesia within the Sherman trap and then released at their initial point of capture.

We used the National Wetlands Inventory (US Fish and Wildlife Service 2011) layer on ArcGIS version
9.3 (Environmental Systems Research Institute, Redlands, California, USA) to select 17 potential study sites. All were palustrine emergent wetlands of 0.4-17.0 ha that were isolated from neighboring wetlands by surrounding uplands. During 13 February-18 May 2011, we surveyed sites for the presence of common reed (Phragmites australis), cattail (Typha spp.), rush (Juncus spp.), sedge (Carex spp.), and standing water to confirm their wetland classification. We charted the boundary of each site by walking the perimeter of wetland vegetation using the Tracks program on a handheld GPS.

To determine rice rat occupancy at wetlands, we placed 1-3 trap lines (each comprising 10 traps $10 \mathrm{~m}$ apart) within emergent vegetation for 3-9 nights 
during February-June 2011. Traps were placed on $15 \times 30 \mathrm{~cm}$ polystyrene foam platforms where standing water was present. Based on high capture rates, we selected four wetlands (Fig. 1) to be used in the permeability study, and set multiple trap lines in each wetland to identify specific areas of high rice rat abundance.

We categorized landcover in and surrounding the four wetland sites as emergent wetlands, agriculture fields, prairie grasslands, hardwood forests, shrubby uplands, rocky lakeshores, irrigation ditches, open water, or gravel roads; and we digitized landcover boundaries using a handheld GPS (Fig. 2). During the 2011 growing season, soybeans were the only crop grown on all agriculture fields except one, which was converted from winter wheat to soybean in July. Within each wetland, we identified 2-3 smaller (0.1-0.3 ha) sub-locations where rice rats were locally abundant and that were bordered by at least one of three landcover types that were the focus of our study: grasslands, agriculture fields or hardwood forests (Fig. 2). Sub-locations were the primary experimental units for the landscape permeability study; three sublocations were bordered by grassland, three by agriculture, one by both grassland and agriculture, and four by forest.

\section{Measuring matrix permeability}

At each sub-location, we performed a 4 week research cycle of collective marking, matrix trapping, habitat trapping, and habitat composition measurements 4-5 times between 7 March 2011 and 3 January 2012. We spent 1 week collectively marking resident rice rats by distributing an ingestible marker within each wetland sub-location, 2 weeks trapping for rice rats on trap lines extending into the adjacent matrix, and 1 week trapping in the sub-location to measure abundance of rice rats. Water depth within wetlands was measured twice during each 2 week matrix trapping period and we measured the vegetative profile at each matrix trap once during each sub-location trapping week. We staggered trap and feeder placement between sublocations to minimize the number of materials needed, and to ensure that marked bait was accessible to wetland residents between trapping sessions.

Trap aversion can be detrimental to capture-markrecapture studies if study species avoid traps after initial capture (Balph 1968; Hammond and Anthony
2006). To combat this, we chose to identify sublocation residents by collectively marking rice rats with the fluorescent ingestible marker rhodamine B (AC13231-1000, Acros Organics, Thermo Fisher Scientific, New Jersey, USA; Mascari and Foil 2009). We combined rhodamine B with mixed birdseed at a $0.5 \mathrm{~g} / \mathrm{kg}$ concentration and distributed it within sub-locations using feeders constructed from $22 \mathrm{~L}$ aluminum buckets with entrances cut into the sides. We placed four feeders 15-25 m apart in each sub-location (Fig. 2) for 1 week before matrix trapping, allowing animals time to ingest the marker. After 1 week of collective marking, we removed feeders from the sub-location to ensure that the bait did not influence movement behavior.

We used the rate of decline in capture rate (probability of a rice rat capture during a trap-night) of rice rats with increasing distance into the matrix to quantify the permeability of unsuitable landcover types. We laid 3-4 trap lines oriented perpendicular to the habitat boundary at each sub-location, each line consisting of Sherman traps placed singly at distances of $0,5,15,25,35,45,55,65,75,85$, and $95 \mathrm{~m}$ into unsuitable cover (Fig. 2). We opened traps 3 nights per week, producing 6 total trap-nights per station for the 2 week period following collective marking. Additionally, we clipped 3-4 whiskers from each rice rat upon capture and examined the whiskers under a HUND H606 fluorescent microscope (Hund Wetzlar, Wetzlar, Germany) for the presence of fluorescent rhodamine bands.

After 2 weeks of matrix trapping, we removed matrix trap lines and used these traps to estimate local rice rat abundance within the wetland sub-locations for the final week of the cycle. We placed 10-30 traps spaced $10 \mathrm{~m}$ apart in a grid overlaying each sublocation (Fig. 2) and opened traps for 3 nights in the week after matrix trapping. We calculated the Minimum Number Known Alive (MNKA) of rice rats at sub-locations during each experimental cycle as an estimate of abundance (Krebs 1999). We measured water depth at each trapping point within each sublocation during matrix trapping weeks (twice per cycle). We calculated median water depth across 2 weeks as a measure of habitat inundation during each experimental cycle. We also measured vegetation-cover density at each matrix trap during sublocation trapping (Table 1) using a Nudds board to estimate the percent of the board visibly obscured at 4 
Fig. 2 Placement of collective-marking feeders, matrix traps, and wetland traps at three sub-locations, for studies of matrix permeability for marsh rice rats (Oryzomys palustris) in wetland site 1 at Burning Star 5 Natural Wildlife Area, Jackson County, Illinois 7 March-21 November 2011. Sublocations within wetlands were selected based upon the concentration of rice rat captures and the adjacent matrix landcover types

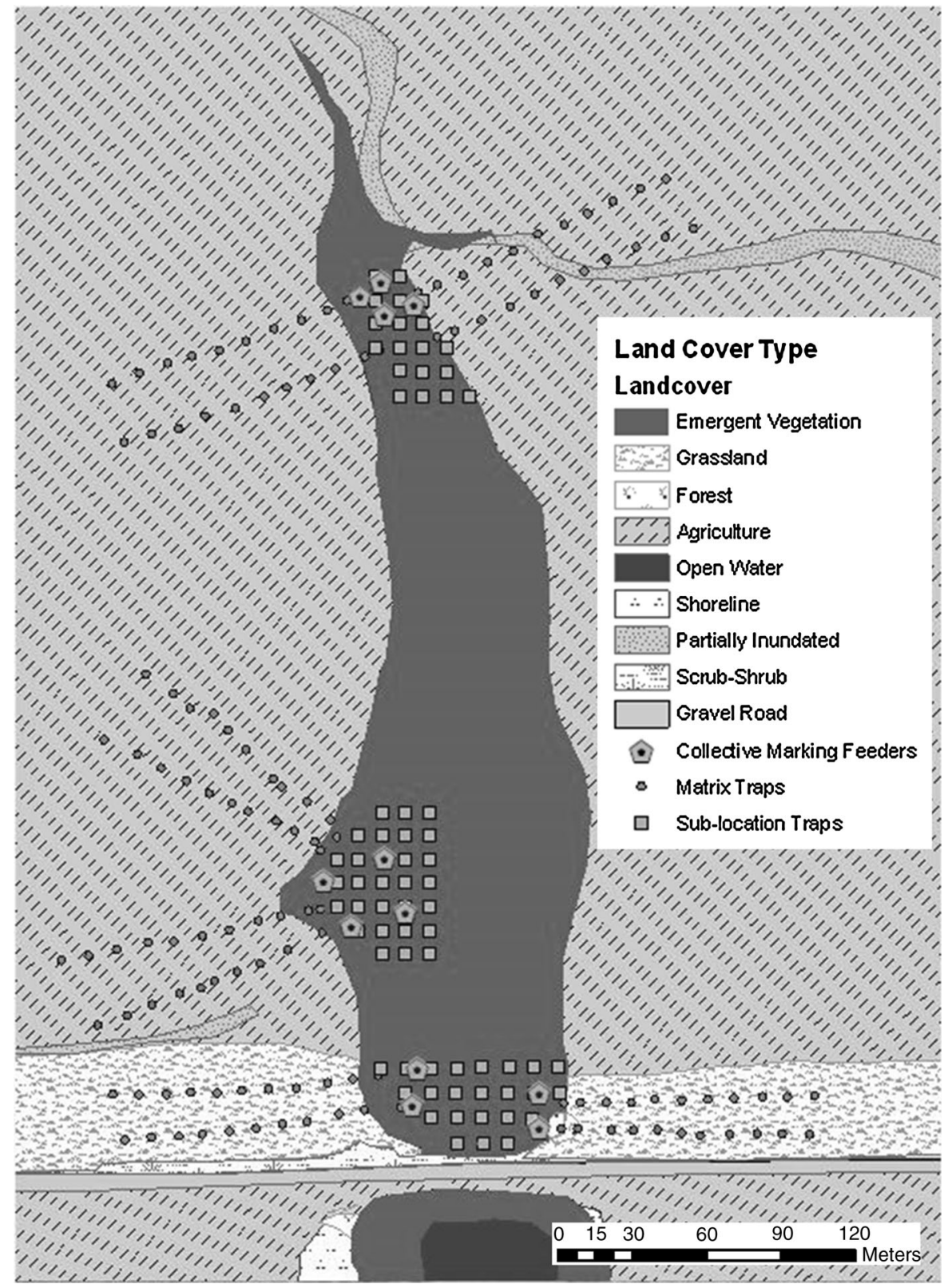

profile heights $(<0.5 \mathrm{~m}, 0.5-1.0 \mathrm{~m}, 1.0-1.5 \mathrm{~m}$, $>1.5 \mathrm{~m}$ ) at a distance of $5 \mathrm{~m}$ from the board (Nudds 1977).

\section{Statistical analysis}

Each 4 week research cycle performed at each sublocation was a sampling period for repeated-measures analysis of matrix capture rates (von Ende 2001). Rice rat capture ( 0 or 1$)$ during a trap-night was the response variable in mixed-model logistic regression, where the estimated probability of capture indicates capture rate. To account for the hierarchical design of our study, we included random variation in intercept values among sub-locations, matrix trapping lines (nested within sub-location), and traps (nested within line) (McCulloch and Searle 2001). Including wetland as a random effect resulted in estimates of zero variance for that term, so it was not included. We ran each analysis with 2 separate datasets of matrix 
Table 1 Number of marsh rice rat (Oryzomys palustris) captures in upland cover types surrounding wetland habitats at Burning Star 5 Natural Wildlife Area (DeSoto, Illinois), 7 March-20 December 2011

\begin{tabular}{lccccc}
\hline Landcover type & Total captures & With rhodamine & With toe-clip & Rhodamine only & Toe-clip only \\
\hline Agriculture & 24 & 13 & 5 & 10 & 1 \\
Grassland & 10 & 9 & 5 & 4 & 1 \\
Forest & 9 & 6 & 3 & 3 & 0 \\
Total & 43 & 28 & 13 & 17 & 2 \\
\hline
\end{tabular}

Rice rats in wetland patches were collectively marked with rhodamine-infused bait, and rice rats captured in wetlands were toeclipped

captures: one containing all rice rat captures and the other with only rhodamine-marked rice rats. All analyses were performed using PROC GLIMMIX in program SAS (Version 9.3; SAS Institute Incorporated, Cary, NC, USA).

Our first objective was to test whether permeability differed among matrix types. Matrix permeability was quantified as the slope coefficient of logit(capture probability) versus distance into the matrix; more negative slopes indicated low permeability. Therefore, meeting this objective required testing for both the main and interactive effects of distance from habitat edge and matrix cover type on rice rat capture rates; a distance $\times$ cover type interaction indicates differential permeability among the matrix types. We also fitted a model without the interaction term to assess the main effects of distance and matrix cover type.

Our second objective was to determine whether permeability near the wetland edge (within the rats' perceptual range) differed from permeability farther into the matrix. To do so, we tested whether the slope of capture rate versus distance from the edge differed between 2 intervals of traps (i.e., distance $\times$ interval interaction): $0-15$ and $25-95 \mathrm{~m}$. The cut-off between distance intervals was based on the rice rat perceptual range of $10 \mathrm{~m}$ as determined by Schooley and Branch (2005) and ensured that 3 distance values were used to estimate permeability within the rats' perceptual range.

Our third objective was to elucidate additional factors influencing matrix use and permeability for rice rats. Use of matrix cover types and permeability of that matrix may be influenced by factors operating at small spatial and temporal scales, which could obscure or explain differences among matrix cover types. For example, rice rats might feel safer venturing away from wetlands if they are hidden by dense vegetation, regardless of the type of vegetation. Alternatively, high local abundance of rice rats could push subordinate individuals (especially subadults) into matrix. We conducted an exploratory analysis (mixed-model logistic regression) of how capture rate varies with the fixed-effect categorical variables of trap distance (kept in all models) and the session-specific continuous covariates of date, population abundance (MNKA), median water depth, and vegetation cover at the 4 profile heights. Due to the relatively small dataset of rice rat captures, each model examined one covariate at a time along with distance, either main effects only (covariate effect on matrix use) or with the interaction between that covariate and distance (covariate effect on matrix permeability).

Finally, we sought to test whether rice rats moving through matrix differed demographically from those in wetland habitats. Specifically, we tested whether the sex $(0=$ Female, $1=$ Male $)$ or age $(0=$ Subadult, $1=$ Adult) composition of captured rice rats differed between matrix and wetland using mixed-model logistic regression, including random variation in intercept values among sub-locations and trapping sessions (nested in sub-location). Random effect variables for sex and age composition analyses differed from those used in the analysis of matrix capture rates because there is no a priori reason to expect lack of independence at scales (trap line, trap) nested within sub-location, but we did expect age and sex composition to vary among trapping sessions.

\section{Results}

A total of 19,051 trap nights were recorded during 14 February 2011-3 January 2012. Effort was divided among occupancy trapping (2560 trap nights), abundance trapping in sub-locations (2881), and matrix trapping for permeability estimates $(13,610)$. 
Throughout the field season, we captured 169 individual marsh rice rats 241 times, producing an overall capture rate of 1.27 rats/100 trap nights. Of the 43 rice rats captured in matrix trap lines, 28 were marked with rhodamine B but only 13 were marked by a toe-clip from previous capture (Table 1). Most matrix captures occurred in the spring and summer and none occurred after September 2011 (Fig. 3). Capture rates in wetland sub-locations also decreased over the course of the season, being lowest in September, October, and November (Fig. 3). Additional small mammals captured in matrix traps were white-footed mice (Peromyscus leucopus), deer mice (Peromyscus maniculatus), prairie voles (Microtus ochrogaster) and house mice (Mus musculus).

Median water depth for the 4 study sites averaged $( \pm \mathrm{SE}) \quad 0.03 \pm 0.01 \mathrm{~m}$ between 15 May and 14 December 2011, though water levels fluctuated greatly over that period. A major flooding event occurred in April 2011 before depth data were collected. Additionally, all 4 wetlands were dry or nearly so during 23 July-14 September 2011 due to high temperatures and infrequent precipitation (Fig. S1). Matrix vegetation cover varied between cover types. Comparing among matrix types, trap stations in forest had the lowest cover density at ground level $(<0.5 \mathrm{~m})$ most of the time, but greatest cover $>1.5 \mathrm{~m}$ throughout the study. In agricultural fields, cover $<1 \mathrm{~m}$ had 2 nadirs, one in
July after the wheat harvest and the other in November-December after soybean harvest (Fig. 4). Cover $<1 \mathrm{~m}$ was consistently higher in grasslands than in other cover types throughout the year (Fig. 4).

Capture rates declined with distance from the wetland edge, and we found marginally significant evidence that the slope of capture rate versus distance (i.e., permeability) differed among cover types for all captured rice rats (Table 2); that slope was less steep for agricultural fields than grassland or forest (Fig. 5). The same general pattern obtained for captures of rhodamine-marked rice rats (Fig. 5), but the distance $\times$ cover type interaction was nonsignificant (Table 2). We could not detect a difference in permeability between traps near $(0-15 \mathrm{~m})$ and at a distance $(25-95 \mathrm{~m})$ from the wetland edge, as the distance $\times$ distance-interval interaction was non-significant for both total captures and rhodamine-marked captures (Table 3).

Matrix capture rates (of all rice rats and of rhodamine-marked rats only) generally decreased over time, increased with rice rat abundance, and increased with visual obstruction at ground level $(<0.5 \mathrm{~m})$. However, no covariates appeared to influence matrix permeability (Table 4). Adults constituted a greater proportion of rice rats captured in wetlands $(65.8 \pm 5.7 \%)$ than matrix types $(59.8 \pm 11.9 \%$; $\left.\mathrm{F}_{1,99}=11.62, P<0.05\right)$. Sex ratio was similar
Fig. 3 Trapping effort and marsh rice rat (Oryzomys palustris) capture rates during 14 February 2011-3 January 2012 at Burning Star 5 Natural Wildlife Area (DeSoto, Illinois) between wetland habitat (dark bars) and matrix landcover (light bars)

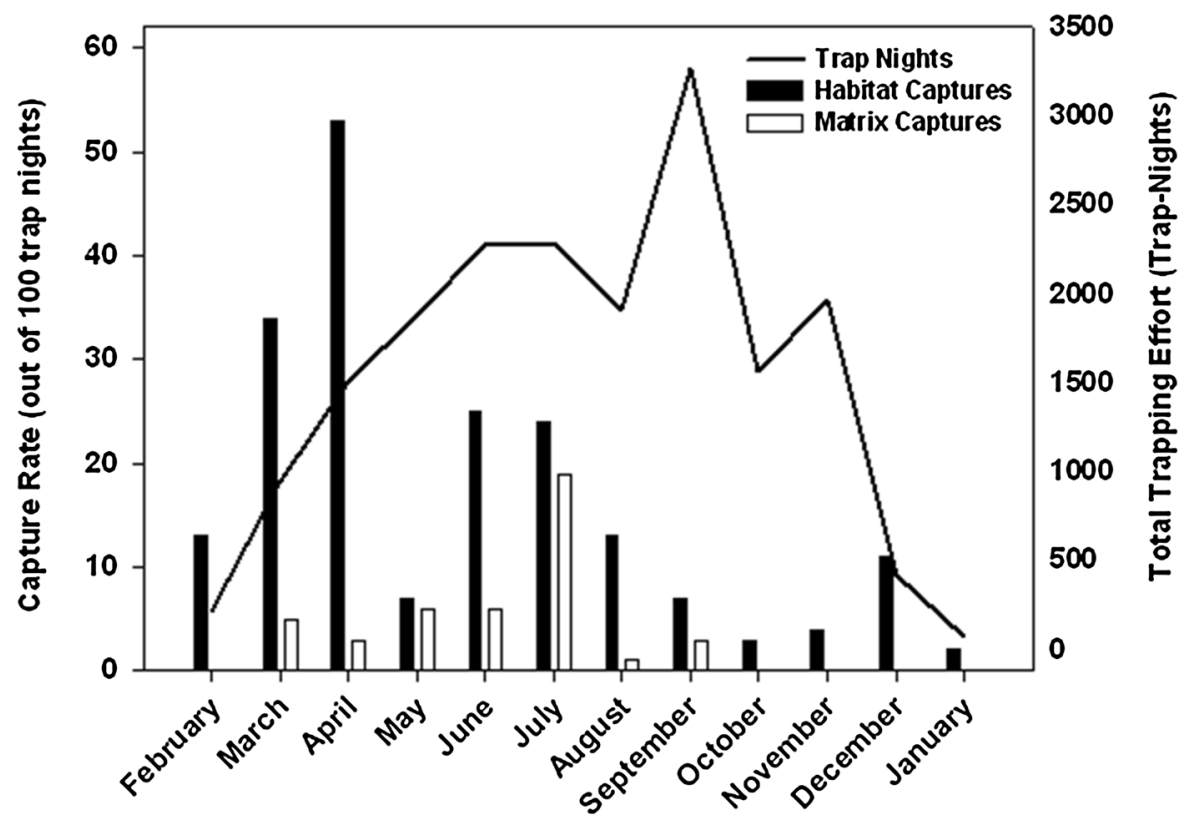


(a)
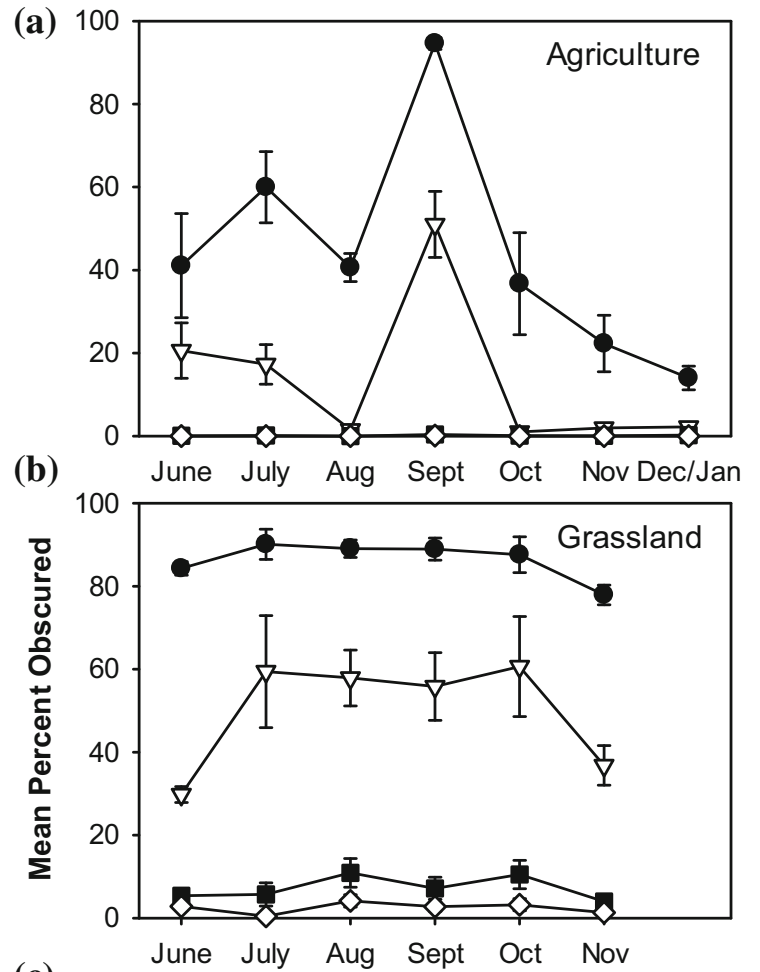

(c)

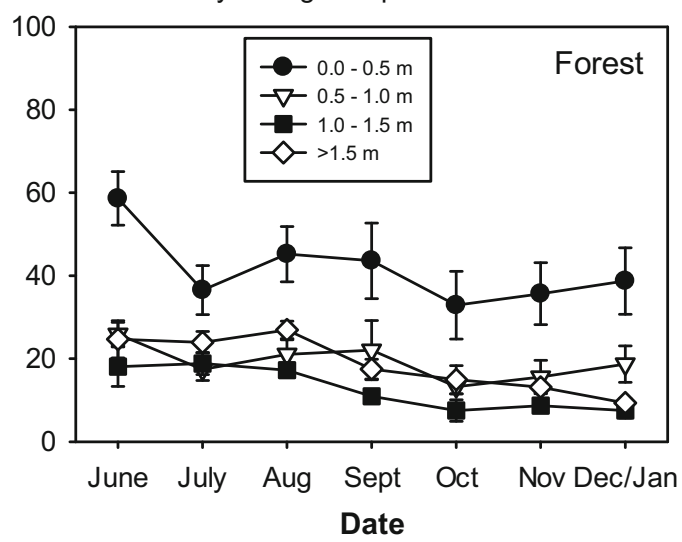

Fig. 4 Average monthly measurements of vegetation cover density (percent of Nudds board obscured) for matrix trap locations within a agricultural fields, $\mathbf{b}$ forest, and $\mathbf{c}$ grasslands at Burning Star 5 Natural Wildlife Area (DeSoto, IL) between June 1 and December 15, 2011

$\left(\mathrm{F}_{1,99}=2.87, P=0.12\right)$ in wetland $(53.2 \pm 6.8 \%$ male) and matrix $(50.7 \pm 10.7 \%$ male $)$.

\section{Discussion}

For species that exist in a highly fragmented, heterogeneous landscape, limited inter-patch movement produces habitat isolation and can lead to regional extirpation (Hanski 1994). When the landscape is absent of clear dispersal corridors, simple connectivity measures like distance to patch and least-cost pathways fail to account for the difference in movement behaviors between individuals (Revilla et al. 2004; Fahrig 2007). Connectivity models can use the resulting differences in landcover permeability to predict dispersal dynamics and landscape occupancy patterns (Revilla et al. 2004; Zeller et al. 2012). We quantified permeability for marsh rice rats in common matrix landcover types of southern Illinois, and also identified key seasonal habitat features that may influence rice rats to leave patches and potentially disperse. Rice rats entered and moved through soybean fields at a higher rate than either forest or grassland cover types, and permeability appeared to be greatest in the agricultural matrix type. We found that rice rats used matrix cover types most often during the summer when ground cover was dense and rice rat populations were high. The clear effect of ground cover in the capture models and higher capture rates in agricultural fields show that rice rats are willing to enter and move through crop fields during the growing season.

Landcover types that are less suitable as habitat are commonly presumed to be less permeable to dispersal, and this notion has empirical support for some species. Rittenhouse and Semlitsch (2006) found that grassland areas acted as a barrier to forest-specialist salamanders, for example. Our results question whether this is true for marsh rice rats. Kruchek (2004) and Wolfe (1982) suggested that grassland is more suitable than other matrix cover types, as it closely resembles emergent wetland vegetation. Indeed, rice rats nest in Everglades sawgrass (Cladium spp.) prairies (Smith and Vrieze 1979), lowland meadows dominated by Bromus spp. (McLaughlin and Robertson 1951), and recently disturbed grasslands (Urbanek and Klimstra 1986). In our study, however, marked rice rats were not captured $>15 \mathrm{~m}$ into grasslands. Conversely, rice rats were captured $85 \mathrm{~m}$ from wetland habitat in soybean fields and upland deciduous forest, which represented the first reported capture of rice rats in these cover types (Goertz and Long 1973; Wolfe 1982; Hofmann et al. 1990; Franz et al. 1998; Miller et al. 2004). These findings suggest that grassland cover could actually hinder long-distance dispersal relative to crop fields. A similar pattern has been observed 
Table 2 Results of testing whether matrix types (agriculture, forest, and grassland) differ in permeability to marsh rice rats (Oryzomys palustris) at Burning Star 5 Natural Wildlife Area (DeSoto, Illinois), 7 March-20 December 2011

\begin{tabular}{|c|c|c|c|c|c|c|c|c|c|}
\hline \multirow[t]{2}{*}{ Model type } & \multirow[t]{2}{*}{ Variable } & \multicolumn{4}{|c|}{ Marked and unmarked } & \multicolumn{4}{|c|}{ Marked only } \\
\hline & & $\mathrm{F}$ & df & $\mathrm{P}$ & Estimate (SE) & $\mathrm{F}$ & df & $\mathrm{P}$ & Estimate (SE) \\
\hline \multirow[t]{10}{*}{ Interactive } & Intercept & & & & $-4.68(0.53)$ & & & & $-5.04(0.63)$ \\
\hline & Distance & 14.11 & 11,215 & $<0.01$ & $-0.049(0.020)$ & 6.98 & 1,1215 & 0.008 & $-0.075(0.041)$ \\
\hline & Cover type & 0.00 & 21,215 & 1.00 & & 0.23 & 2,1215 & 0.79 & \\
\hline & Agriculture & & & & $0.01(0.70)$ & & & & $-0.27(0.83)$ \\
\hline & Forest & & & & $0.06(0.75)$ & & & & $0.25(0.82)$ \\
\hline & Grassland & & & & 0 & & & & 0 \\
\hline & Distance $\times$ cover type & 2.92 & 21,215 & 0.054 & & 2.18 & 2,1215 & 0.11 & \\
\hline & Agriculture & & & & $0.039(0.021)$ & & & & $0.068(0.042)$ \\
\hline & Forest & & & & $0.005(0.026)$ & & & & $0.035(0.045)$ \\
\hline & Grassland & & & & 0 & & & & 0 \\
\hline \multirow[t]{6}{*}{ Main effects } & Intercept & & & & $-5.21(0.48)$ & & & & $-5.83(0.56)$ \\
\hline & Distance & 12.84 & 11,217 & $<0.01$ & $-0.023(0.006)$ & 8.03 & 1,1217 & $<0.01$ & $-0.024(0.008)$ \\
\hline & Cover type & 1.86 & 21,217 & 0.16 & & 1.51 & 2,1217 & 0.22 & \\
\hline & Agriculture & & & & $0.98(0.57)$ & & & & $1.07(0.62)$ \\
\hline & Forest & & & & $0.14(0.64)$ & & & & $0.69(0.66)$ \\
\hline & Grassland & & & & 0 & & & & 0 \\
\hline
\end{tabular}

Permeability is indicated by the slope of logit (capture rate) with distance from the wetland edge. Tests and slope estimates are from mixed-model logistic regression, using random effects to account for nonindependence based on wetland sublocation, trap line, and trap station

repeatedly for white-tailed deer (Odocoileus virginianus), a species that requires woody cover but shows greater dispersal rates and distances in landscapes dominated by open grasslands and agricultural fields (Nixon et al. 1991, 1994; Long et al. 2005, 2008).

Wetland connectivity within a heavily agricultural landscape is important to ensure the persistence of marsh rice rat populations at the northern periphery of their geographic range (Wolfe 1982; Eubanks 2009). In Illinois, rice rats are believed to use waterways, partially inundated ditches, and roadside rights-ofway as primary dispersal corridors (Hofmann et al. 1990; Eubanks et al. 2011). Our findings suggest that, in the absence of primary dispersal corridors, agricultural fields may have greater potential than grassland or forest for enabling rice rats to move between wetlands. Although rice rats have historically been considered pests in inundated rice fields (Harlan 1837), it is unlikely that rice rats were entering agriculture fields solely to forage for soybeans. No rats were captured in crop fields during soybean harvest (late September-October) when mature beans were most available. Rather, mature soybean plants may permit long-distance movement by virtue of the dense leaf canopy and relatively open ground at the base of the stalk. The linear structure of crop rows may also promote long distance movement by rice rats, as has been observed for small rodents in Italy (Sozio et al. 2013) and for Brazilian marsupials (Prevedello and Vieira 2010).

We captured marsh rice rats in the matrix more often at times and locations of high vegetation cover and high population abundance. The well-known preference of rice rats for dense groundcover near wetlands (Hofmann et al. 1990; Negus et al. 1961) was recently substantiated by Eubanks et al. (2011), who found wetland occupancy by rice rats was highly correlated with vegetation $<0.5 \mathrm{~m}$ and negatively correlated with bare ground. Rice rats likely seek refuge in vegetation that provides high visual obstruction from vision-based predators such as Northern harrier (Circus cyaneus), barn owl (Tyto alba), and mink (Mustela vison; Wolfe 1982). Rice rats also entered the matrix at a higher rate during peaks in population abundance. High rice rat abundance may force individuals to move into suboptimal cover to avoid indirect and direct competition 

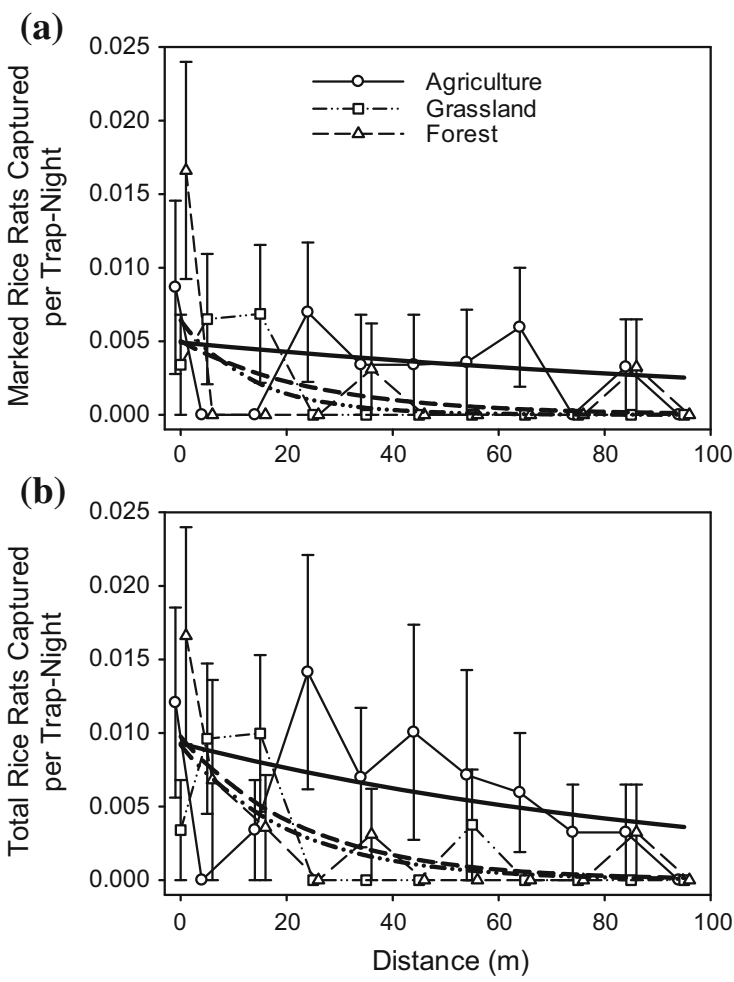

Fig. 5 Relationship between the matrix capture rate of a rhodamine-marked marsh rice rats (Oryzomys palustris) or b total marsh rice rats and the distance of traps from the habitat edge at Burning Star 5 Natural Wildlife Area (DeSoto, IL), 7 March-20 December 2011

from other rice rats (Gaines and McClenaghan 1980). Like Kruchek (2004), we found that subadults were disproportionately captured in the matrix compared to adults, which may be the result of resource partitioning or natal dispersal in the species. Capture rates in both wetland and matrix decreased over the course of the season, which corresponded with decreasing water levels (date vs. median depth $r=-0.37$ ). Wetlands at Burning Star 5 reached their lowest water levels from mid-August through October, which also paralleled a drop in total capture rate. Low trappability may have influenced the apparent effect of water depth on permeability, as no rice rats were captured in the matrix between October and December when water levels rose again. The literature on rice rat movement in response to flooding is mixed, as Kruchek (2004) found large shifts in abundance during periods of inundation whereas Abuzeineh et al. (2007) found little. In southern Illinois, rice rat matrix movements appeared to increase as individuals left dry wetlands to potentially seek out permanent water sources (Cooney 2012). Current studies examining the metapopulation dynamics of rice rats in southern Illinois are also testing whether ephemeral wetlands have a higher probability of patch extirpation than permanent wetlands (van der Merwe 2014).

Although connectivity is modeled at the scale of the landscape (Ricketts 2001), the decision to disperse is made at the perceptual level of the individual (Revilla et al. 2004; Fahrig 2007). Lidicker (1999) notes that, at a certain distance from the habitat, edge-mediated behavior would give way to behavior that is purely dictated by the animal's reaction to the matrix. In keeping with that prediction, Prevedello et al. (2010)

Table 3 Results of testing whether matrix permeability to marsh rice rats (Oryzomys palustris) differed between traps near (0-15 m) and far from (25-95 m) the wetland edge, at Burning Star 5 Natural Wildlife Area (DeSoto, Illinois), 7 March-20 December 2011

\begin{tabular}{|c|c|c|c|c|c|c|c|c|}
\hline \multirow[t]{2}{*}{ Variable } & \multicolumn{4}{|c|}{ Marked and unmarked } & \multicolumn{4}{|c|}{ Marked only } \\
\hline & $\mathrm{F}$ & df & $\mathrm{P}$ & Estimate (SE) & $\mathrm{F}$ & df & $\mathrm{P}$ & Estimate (SE) \\
\hline Intercept & & & & $-4.70(0.39)$ & & & & $-4.74(0.39)$ \\
\hline Distance & 2.31 & 1,1217 & 0.13 & $-0.042(0.041)$ & 3.89 & 1,1217 & 0.049 & $-0.11(0.06)$ \\
\hline Interval & 0.01 & 1,1217 & 0.91 & & 0.89 & 1,1217 & 0.35 & \\
\hline $0-15 \mathrm{~m}$ & & & & 0 & & & & 0 \\
\hline $25-95 \mathrm{~m}$ & & & & $-0.078(0.69)$ & & & & $-0.85(0.90)$ \\
\hline Distance $\times$ interval & 0.19 & 1,1217 & 0.19 & & 2.17 & 1,1217 & 0.14 & \\
\hline $0-15 \mathrm{~m}$ & & & & 0 & & & & 0 \\
\hline $25-95 \mathrm{~m}$ & & & & $0.019(0.043)$ & & & & $0.095(0.064)$ \\
\hline
\end{tabular}

Permeability is indicated by the slope of logit (capture rate) with distance from the wetland edge. Tests and slope estimates are from mixed-model logistic regression using random effects to account for nonindependence based on wetland sublocation, trap line, and trap station 
Table 4 Results of exploratory analysis (mixed-model logistic regression) of factors affecting captures of marsh rice rats (Oryzomys palustris) in upland matrix surrounding wetlands at
Burning Star 5 Natural Wildlife Area (DeSoto, Illinois), 7 March-20 December 2011

\begin{tabular}{|c|c|c|c|c|}
\hline \multirow[t]{2}{*}{ Covariate } & \multicolumn{2}{|l|}{ Marked only } & \multicolumn{2}{|l|}{ Marked + unmarked } \\
\hline & $\begin{array}{l}\text { Matrix use } \\
\text { (main effect) }\end{array}$ & $\begin{array}{l}\text { Permeability } \\
\text { (interaction with distance) }\end{array}$ & $\begin{array}{l}\text { Matrix use } \\
\text { (main effect) }\end{array}$ & $\begin{array}{l}\text { Permeability } \\
\text { (interaction with distance) }\end{array}$ \\
\hline Date & $-0.013 \pm 0.005^{*}$ & Convergence failed & $-0.016 \pm 0.004 * *$ & Convergence failed \\
\hline \multicolumn{5}{|l|}{ Depth $^{\mathrm{a}}$} \\
\hline MNKA $^{\mathrm{b}}$ & $0.28 \pm 0.09 * *$ & & $0.32 \pm 0.08 * *$ & \\
\hline Cover $<0.5 \mathrm{~m}^{\mathrm{c}}$ & $0.023 \pm 0.012^{*}$ & & $0.027 \pm 0.009 * *$ & \\
\hline \multicolumn{5}{|l|}{ Cover $0.5-1.0 \mathrm{~m}$} \\
\hline Cover $1.0-1.5 \mathrm{~m}$ & & Convergence failed & & \\
\hline Cover $>1.5 \mathrm{~m}$ & Convergence failed & Convergence failed & & Convergence failed \\
\hline
\end{tabular}

observed more linear movements by didelphid marsupials within perceptual range of habitat patches than beyond. We did not find evidence that marsh rice rats behaved differently when outside their perceptual range from the habitat, as we did not detect a difference in permeability $\leq 15 \mathrm{~m}$ versus $\geq 25 \mathrm{~m}$. Perceptual range may not be the best index of patch detectability, as Schooley and Branch (2005) found that rice rats released in the matrix were more likely to move parallel to wind direction than towards a nearby wetland. Also, it is possible that resident rice rats perceive or remember wetland locations at distances greater than the $10 \mathrm{~m}$ perceptual range estimated by Schooley and Branch (2005). Cooney (2012) found rice rats moving $>300 \mathrm{~m}$ through the matrix in a single night, which suggests that trapping at $10 \mathrm{~m}$ increments up to $95 \mathrm{~m}$ into unsuitable cover may not have reflected the scale at which rice rats differentiate between edge and matrix conditions. Finally, breaking the dataset into distance intervals necessarily reduces power and inflates uncertainty in coefficient estimates, particularly for permeability within the rice rats' perceptual range (based on 3 distance values). The large standard errors for the interaction coefficient (Table 4) indicate that permeability could have differed substantially between distance intervals or not at all. Future research aimed specifically at testing for differential permeability based on perceptual range would benefit from large sample size and empirically characterizing perceptual range of free-moving individuals.

Although we found that agriculture fields appear to be more permeable to rice rats than grassland and forest cover, this behavioral response would not necessarily lead to higher landscape connectivity if dispersal across agriculture is not ultimately successful (Hanski 1994). Fahrig (2007) suggests that animals may perceive human-modified matrix types as highquality, but long-distance movement within such matrix can be maladaptive. Movement through agriculture fields could produce a kind of ecological trap, where animals readily enter a cover type despite an increased risk of mortality (Fahrig 2007). For a species adapted to semi-aquatic environments and their surrounding uplands, agriculture may ultimately prevent successful dispersal if rice rats face greater predation or starvation in crop fields than in native cover types (Gaines and McClenaghan 1980). In southern Illinois, Eubanks et al. (2011) found that wetland patches surrounded by agriculture were less likely to be occupied by rice rats than those surrounded by upland grasses, but survival rates have not been explicitly compared between wetland and matrix areas.

An important application of empirical measures of landcover permeability is an improved ability to predict habitat connectivity and population persistence. Estimating connectivity in the heterogeneous matrix can aid managers in selecting portions of the 
landscape where restoration can enhance movement between patches and combat fragmentation (Revilla et al. 2004). The present study confirms that longdistance movement through crop fields is possible and likely, but future research should focus on whether this movement results in high levels of inter-patch connectivity in rice rat populations. An alternative to our trap-based measure of matrix permeability is the use of small-scale genetic structuring among populations in a metapopulation to map gene transmission across the landscape (McRae 2006). For an imperiled population like marsh rice rats in southern Illinois, promoting successful dispersal between isolated habitats can stabilize populations by decreasing genetic isolation and increasing the colonization potential of uninhabited sites (Hanski 1994).

Acknowledgments Funding for this project was provided by the Illinois Department of Natural Resources (Federal Aid Project W-135-R) and the Graduate School at Southern Illinois University Carbondale. We thank the National Wild Turkey Federation and CONSOL Energy for cooperation and study site access. We thank Robert Schooley for advisory input and comments on the Master's thesis (Cooney 2012) upon which this manuscript was based. This manuscript was substantially improved by constructive criticism from two anonymous reviewers.

Conflict of interest The authors declare that they have no conflict of interest.

Open Access This article is distributed under the terms of the Creative Commons Attribution License which permits any use, distribution, and reproduction in any medium, provided the original author(s) and the source are credited.

\section{References}

Abuzeineh AA, Owen RD, McIntyre NE, Dick CS, Strauss RE, Holsomback T (2007) Response of marsh rice rats (Oryzomys palustris) to inundation of habitat. Southwest Nat 52:75-78

Balph DF (1968) Behavioral responses of unconfined Uinta ground squirrels to trapping. J Wildl Manag 32:778-794

Bode M, Burrage K, Possingham HP (2008) Using complex network metrics to predict the persistence of metapopulations with asymmetric connectivity patterns. Ecol Model 214:201-209

Bowne DR, Peles JD, Barrett GW (1999) Effects of landscape spatial structure on movement patterns of the hispid cotton rat (Sigmodon hispidus). Landscape Ecol 14:53-65

Cooney SA (2012) Landscape permeability and home range composition of the marsh rice rat (Oryzomys palustris) in southern Illinois. Thesis, Southern Illinois University, Carbondale

Delahunt KS (2011) Nesting ecology, survival, and home range of wild turkey in an agricultural landscape. Thesis, Southern Illinois University, Carbondale

Eubanks BW (2009) Status and distribution of the state-threatened marsh rice rat (Oryzomys palustris) in Illinois. Thesis, Southern Illinois University, Carbondale

Eubanks BW, Hellgren EC, Nawrot JR, Bluett RD (2011) Habitat associations of the marsh rice rat (Oryzomys palustris) in freshwater wetlands of southern Illinois. J Mamm 92:552-560

Fahrig L (2007) Non-optimal animal movement in human-altered landscapes. Funct Ecol 21:1003-1015

Franz R, Maehr D, Kinlaw A, O'Brien C, Owen RD (1998) Distribution and abundance of sensitive wildlife species at Avon Park Air Force Range. Final Report to the Department of Defense. RWO-169

Gaines MS, McClenaghan LR Jr (1980) Dispersal in small mammals. Ann Rev Ecol Syst 11:163-196

Gobeil J-F, Villard M-A (2002) Permeability of three boreal forest landscape types to bird movements as determined from experimental translocations. Oikos 98:447-458

Goertz JW, Long RC (1973) Habitat of five species of rat in Louisiana. Am Midl Nat 90:460-465

Hammond EL, Anthony RG (2006) Mark-recapture estimates of population parameters for selected species of small mammals. J Mamm 87:618-627

Hanski I (1994) A practical model of metapopulation dynamics. J Anim Ecol 63:151-162

Harlan R (1837) Description of a new species of quadruped, of the Order Rodentia, inhabiting the United States; by R. Harlan, M.D. Mus palustris. Am J Sci 31:385-386

Haynes KJ, Cronin JT (2006) Interpatch movement and edge effects: the role of behavioral responses to the landscape matrix. Oikos 113:43-54

Hofmann JE, Gardner JE, Morris MJ (1990) Distribution, abundance, and habitat of the marsh rice rat (Oryzomys palustris) in southern Illinois. Trans Ill State Acad Sci 83:162-180

Illinois Department of Natural Resources (2011) Burning Star 5 Wildlife Management Area. Hunter Fact Sheet 2011-2012. http://dnr.state.il.us/lands/landmgt/hunter_fact_sheet/r5hfs/ brs5.htm. Accessed February 2011

Krebs CJ (1999) Ecological methodology. Benjamin Cummings, San Francisco

Kruchek BL (2004) Use of tidal marsh and upland habitats by the marsh rice rat (Oryzomys palustris). J Mamm 85:569-575

Kuefler D, Hudgens B, Haddad NM, Morris WF, Thurgate N (2010) The conflicting role of matrix habitats as conduits and barriers for dispersal. Ecology 91:944-950

Lidicker WZ Jr (1999) Responses of mammals to habitat edges: an overview. Landscape Ecol 14:333-343

Long ES, Diefenbach DR, Rosenberry CS, Wallingford BD, Grund MRD (2005) Forest cover influences dispersal distance of white-tailed deer. J Mamm 86:623-629

Long ES, Diefenbach DR, Rosenberry CS, Wallingford BD (2008) Multiple proximate and ultimate causes of natal dispersal in white-tailed deer. Behav Ecol 19:1235-1242

Mascari TM, Foil LD (2009) Evaluation of Rhodamine B as an orally delivered biomarker for rodents and a feed-through 
transtadial biomarker for phlebotomine sand flies (Diptera: Psychodidae). J Med Entomol 46:1131-1137

McCulloch CE, Searle SR (2001) Generalized, linear, and mixed models. Wiley, New York

McLaughlin CA, Robertson WB (1951) A new record of the rice rat, Oryzomys palustris palustris, from southern Illinois. Chic Acad Sci Nat Hist Misc Note 80:1-2

McRae BH (2006) Isolation by resistance. Evolution 601:1551-1561

Miller DA, Thill RE, Melchiors MA, Wigley TB, Tappe PA (2004) Small mammal communities of streamside zones in intensively managed pine forests of Arkansas. For Ecol Manag 203:381-393

Moilanen A, Nieminen M (2002) Simple connectivity measures in spatial ecology. Ecology 83:1121-1145

Negus NC, Gould E, Chipman RK (1961) Ecology of the rice rat, Oryzomys palustris (Harlan), on Brenton Island, Gulf of Mexico, with a critique of the social stress theory. Tulane Stud Zool 8:94-123

Nixon CM, Hansen LP, Brewer PA, Chelsvig JE (1991) Ecology of white-tailed deer in an intensively farmed region of Illinois. Wildl Monogr 118:1-77

Nixon CM, Hansen LP, Brewer PA, Chelsvig JE, Sullivan JB, Esker TL, Koerkenmeier R, Etter DR, Cline J, Thomas JA (1994) Behavior, dispersal, and survival of male whitetailed deer in Illinois. Ill Nat Hist Surv Biol Notes 139:1-29

Nudds TD (1977) Quantifying the vegetative structure of wildlife cover. Wildl Soc Bull 5:113-117

Prevedello JA, Vieira MV (2010) Plantation rows as dispersal routes: a test with didelphid marsupials in the Atlantic Forest, Brazil. Biol Conserv 143:131-135

Prevedello JA, Forero-Medina G, Vieira MV (2010) Movement behavior within and beyond perceptual ranges in three small mammals: effects of matrix type and body mass. J Anim Ecol 79:1315-1323

Qin H, Flint C (2000) Southern Illinois land use. Department of Natural Resources and Environmental Science, University of Illinois, Champaign

Rehmeier RL, Kaufman GA, Kaufman DW (2004) Long-distance movements of the deer mouse in tallgrass prairie. J Mamm 85:562-568

Remy A, le Galliard J-F, Gundersen G, Steen H, Andreassen HP (2011) Effects of individual condition and habitat quality on natal dispersal behavior in a small rodent. J Anim Ecol 80:929-937

Revilla E, Thorsten W, Palomares F, Ferreras P, Delibes M (2004) Effects of matrix heterogeneity on animal dispersal: from individual behavior to metapopulation-level parameters. Am Nat 164:E130-E153

Ricketts TH (2001) The matrix matters: effective isolation in fragmented landscapes. Am Nat 158:87-99

Rittenhouse TAG, Semlitsch RD (2006) Grasslands as movement barriers for a forest-associated salamander: migration behavior of adult and juvenile salamanders at a distinct habitat edge. Biol Conserv 131:14-22
Roe JH, Brinton AC, Georges A (2009) Temporal and spatial variation in landscape connectivity for a freshwater turtle in a temporally dynamic wetland system. Ecol Appl 19:1288-1299

Schooley RL, Branch LC (2005) Limited perceptual range and anemotaxis in marsh rice rats, Oryzomys palustris. Acta Theriol 50:59-66

Schooley RL, Wiens JA (2004) Movement of cactus bugs: patch transfers, matrix resistance, and edge permeability. Landscape Ecol 19:801-810

Smith AT, Vrieze JM (1979) Population structure of Everglades rodents: responses to a patchy environment. J Mammal 60:778-794

Sozio G, Mortelliti A, Boitani L (2013) Mice on the move: wheat rows as a means to increase permeability in agricultural landscapes. Biol Conserv 165:198-202

Stamps JA, Buechner M, Krishnan VV (1987) The effects of edge permeability and habitat geometry on emigration from patches of habitat. Am Nat 129:533-552

Suloway L, Hubbell M (1994) Wetland resources of Illinois. Special Publication 15. Illinois Natural History Survey, Champaign

Taylor PD, Fahrig L, Henein K, Merriam G (1993) Connectivity is a vital element of landscape structure. Oikos 68:571-573

Tefler S, Holt A, Donaldson R, Lambin X (2001) Metapopulation processes and persistence in remnant water vole populations. Oikos 95:31-42

Urbanek RP, Klimstra WD (1986) Vertebrates and vegetation on a surface-mined area in southern Illinois. Trans Ill St Acad Sci 79:175-187

US Fish and Wildlife Service (2011) National Wetlands Inventory. FWS Wetlands Mapper. http://www.fws.gov/ wetlands/Data/Mapper.html. Accessed February 2011

van der Merwe J (2014) Ecology of the marsh rice rat (Oryzomys palustris) in southern Illinois: wetland dynamics, metapopulations, and trophic position. Dissertation, Southern Illinois University Carbondale

von Ende CN (2001) Repeated-measures analysis: growth and other time-dependent measures. In: Scheiner S, Gurevitch J (eds) The design and analysis of ecological experiments. Oxford University Press, Oxford, pp 134-157

Wiens JA, Craford CS, Gosz JR (1985) Boundary dynamics: a conceptual framework for styding landscape ecosystems. Oikos 45:421-427

Wolfe JL (1982) Oryzomys palustris. Mamm Species 176:1-5

Wolfe JL (1985) Population ecology of the rice rat (Oryzomys palustris) in a coastal marsh. J Zool 205:235-244

Zeller KA, McGarigal K, Whiteley AR (2012) Estimating landscape resistance to movement: a review. Landscape Ecol 27:777-797

Zollner PA, Lima SL (1999) Search strategies for landscapelevel interpatch movements. Ecology 80:1019-1030 